\title{
PSYCHE
}

\begin{tabular}{lll}
\hline Vol. 100 & 1993 & Nos. 1-2 \\
\hline
\end{tabular}

\section{A TECHNIQUE FOR EFFICIENT SORTING OF LIVE TERMITES FROM DEBRIS}

\author{
By Barbara L. Thorne AND NANCy L. Breisch \\ Department of Entomology \\ University of Maryland \\ College Park, MD 20742-5575
}

\section{INTRODUCTION}

Sorting live termites from nest debris or soil is normally a laborintensive procedure. Heavily populated nest sections or pieces of infested wood can be tapped over a collection dish, yielding satisfying results at first but often diminishing rewards as termites hold on tenaciously or retreat to central cavities. Further, the process of tapping invariably also produces small pieces of debris as contaminants in the collection tray. Those particles are unacceptable for clean samples for such purposes as reference collections, chemical or DNA analyses, weights, or volumetric samples. In these circumstances, a second stage "clean sort" is necessary.

Among the techniques for picking out termites one by one, featherweight forceps are effective if administered gently. Some people prefer to use aspirators, but these should be limited to reverse-flow aspirators because of the hazard of lung infection from inhaling soil microbes or fungal spores present amidst termite debris. The receiving vial of an aspirator must be emptied frequently to avoid insect damage due to crowding. Soldier termites with defense secretions may obstruct aspirator suction tubes.

Termitologists with sufficient patience use small paintbrushes to separate termites, nudging them towards a target receptacle or

Manuscript received 12 February 1993. 
waiting for them to crawl onto the brush, then collecting them with a quick flick into a container. Narrow cardboard strips (or folded index cards) are used in the same manner.

Termite biologists use a variety of techniques to separate larger numbers of termites from broken nest fragments, splintered wood or soil. "Papering off" or "carding" termites works well for many species (Gay et al. 1955, McMahan and Watson 1977). In this approach one places a piece of paper or an index card on an active section of debris, letting the termites crawl onto the paper. Many species respond well to vertical positioning of the paper surface. When the card accumulates a large number of exploring termites, it is moved over to a collecting dish and tapped or flicked to dislodge the insects. The procedure is repeated as desired for collecting or sampling. Corrugated cardboard or moist paper towels are standard substrate variants for this technique, depending on conditions and the species under study.

Sieves with moisture below (eg. a container of moist sand or filter paper) and/or heat above (light bulb) can work well to encourage termites to sort themselves from other substrates by crawling through the sieve screen and dropping to the container below. Caution must be taken, however, to check the apparatus frequently to avoid dessication.

In studies in which entire nests have been fumigated, water flotation methods are used to separate dead termites from nest and particle debris (Wiegert 1970, Darlington 1984).

\section{Subterranean Termites Self-Sort into Plastic Tubing}

Isolating large numbers of subterranean termites from wood and soil debris is particularly challenging. These insects are typically small and delicate, and mortality from handling can be substantial with standard methods of obtaining clean samples. We describe here a quick, effective and inexpensive technique for sorting live Reticulitermes from debris. We have tested the technique with $R$. flavipes (Kollar), $R$. virginicus (Banks) and $R$. hesperus Banks. This approach may well be generalized or adapted for use with other termite genera.

Remove termites from their host substrate by tapping occupied sections over a collection tray or flat container. Splinters of wood debris, termite galleries and soil will also rain into the collection 
arena. Large fragments of wood should be removed to reduce harborage for the termites. After this initial crude separation, lay lengths of flexible plastic tubing (3/16" internal diameter; $1 / 4$ " outside diameter) in the collection tray, positioned such that the open ends are accessible to termites and the tube lies relatively flat. Termites frequently travel along the perimeter of containers, so prudent placement of tube ends intersects these routes (especially corners). Open ends are best cut at angles rather than straight to expose more surface area at the opening. Tube length is not important, but $10-20 \mathrm{~cm}$ sections are convenient.

Termites will soon begin to crawl into the tubes, packing in tightly with immigration greatly exceeding emigration. Termites prefer tight spaces over open areas, and are thus cooperative in remaining in the tubes. Leave the termites to self-sort; depending on numbers and activity level an interval of 10-60 minutes should yield good results.

When a tube is filled or sufficiently occupied, carefully lift it over a second collecting vessel and gently tap out the termites. Alternatively, a longer length of collection tubing (eg. 1 meter) can be draped over the edge of a lab bench, with one or both ends positioned in a new collection receptacle. Termites crawl out of the tubing into the container, eliminating the need for handling or disturbance. Replace the tubing for additional sampling. "Conditioned" tubes (previously occupied by termites, or formerly used as transit connections between two containers of termites) will outperform clean tubing, but ultimately even new tubes will entice termites.

The tube technique can be used in conjunction with other methods; for example lengths of tubing placed in the collection receptacle under a sieve or Berlese sorting apparatus will attract dislodged termites and thus reduce dessication stress.

The tube technique has a number of advantages over many other methods to collect Reticulitermes. After a quick, crude initial separation the biologist need return only occasionally to retrieve groups of uninjured, protected, debris-free specimens.

\section{Literature Cited}

DARLington, J. P. E. C.

1984. A method for sampling the populations of large termite nests. Ann. Appl. Biol. 104: 427-436. 
Gay, F. J., Greaves, T., Holdaway, F. G., Weatherly, A. H.

1955. Standard laboratory colonies of termites for evaluating the resistance of timber, timber preservatives, and other materials to termite attack. CSIRO, Bulletin \#227, Melbourne, 60 pp.

MCMahan, E. A., Watson, J. A. L.

1977. The effect of separation by "papering" on caste ratios in Nasutitermes exitiosus (Hill) (Isoptera). J. Aust. Ent. Soc. 16: 455-457.

WIEGERT, R. G.

1970. Energetics of the nest-building termite, Nasutitermes costalis (Holmgren), in a Puerto Rican forest. In: Odum, H. T. A Tropical Rain Forest. Division of Technical Information, U. S. Atomic Energy Commission. pp. 57-64. 

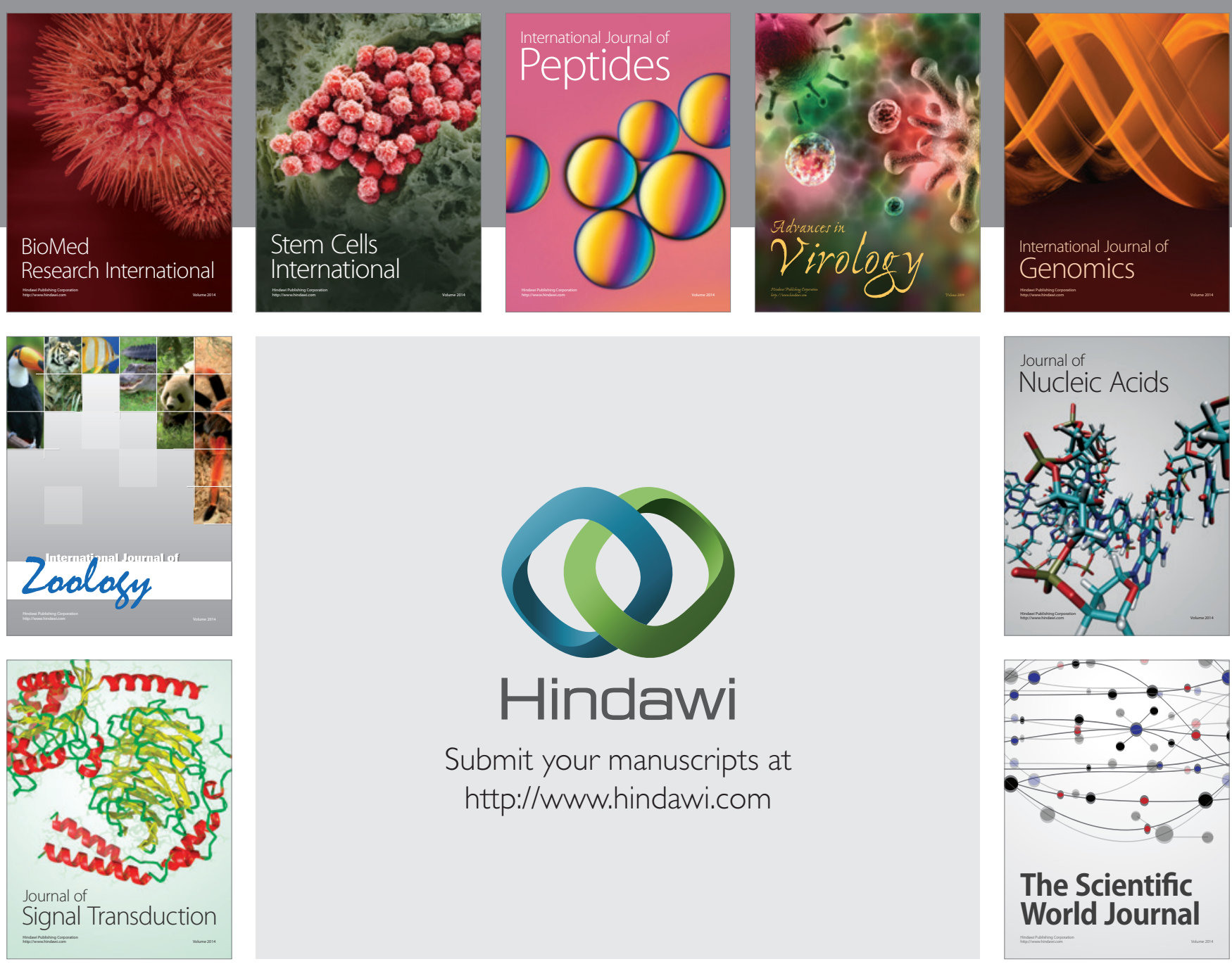

Submit your manuscripts at

http://www.hindawi.com
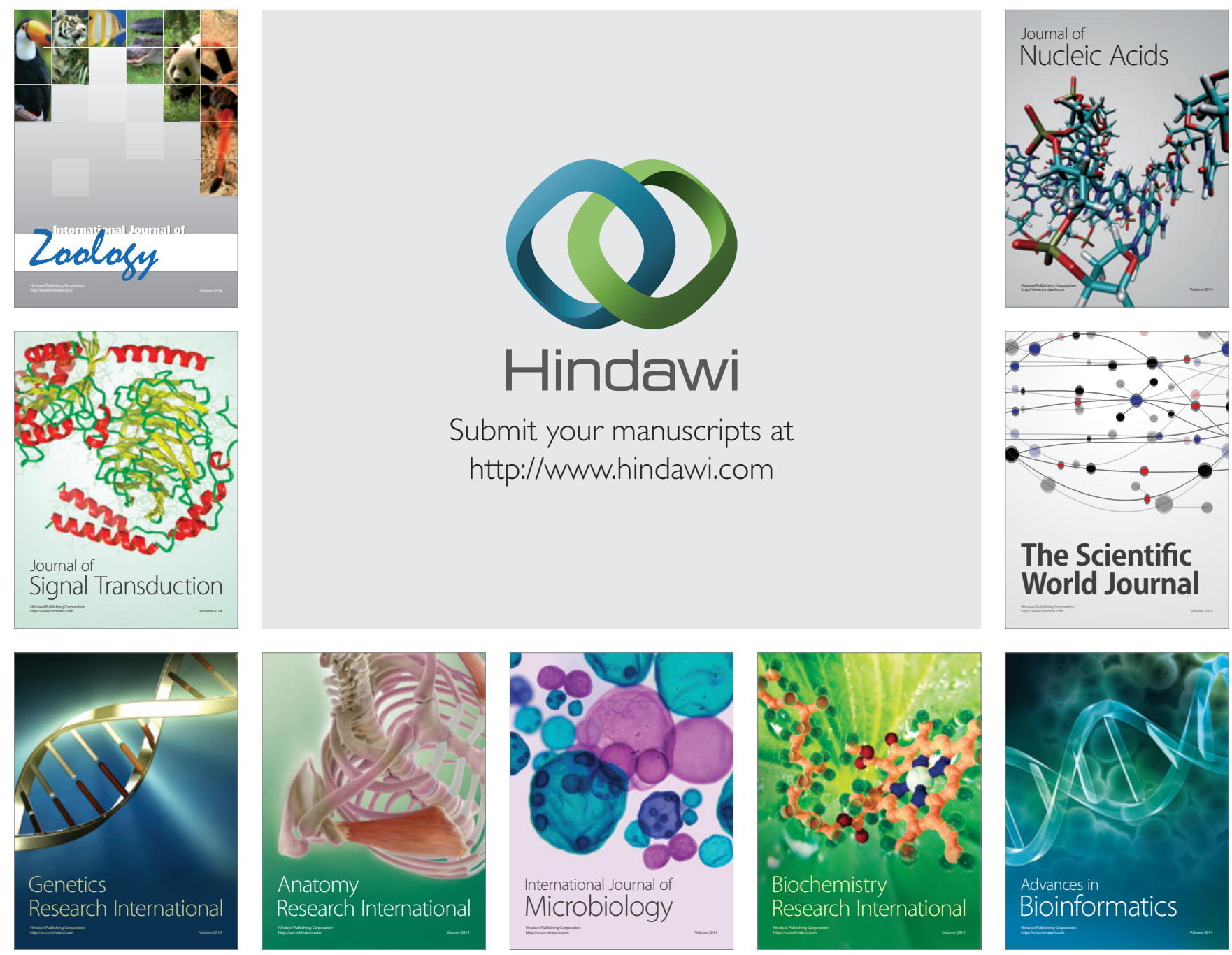

The Scientific World Journal
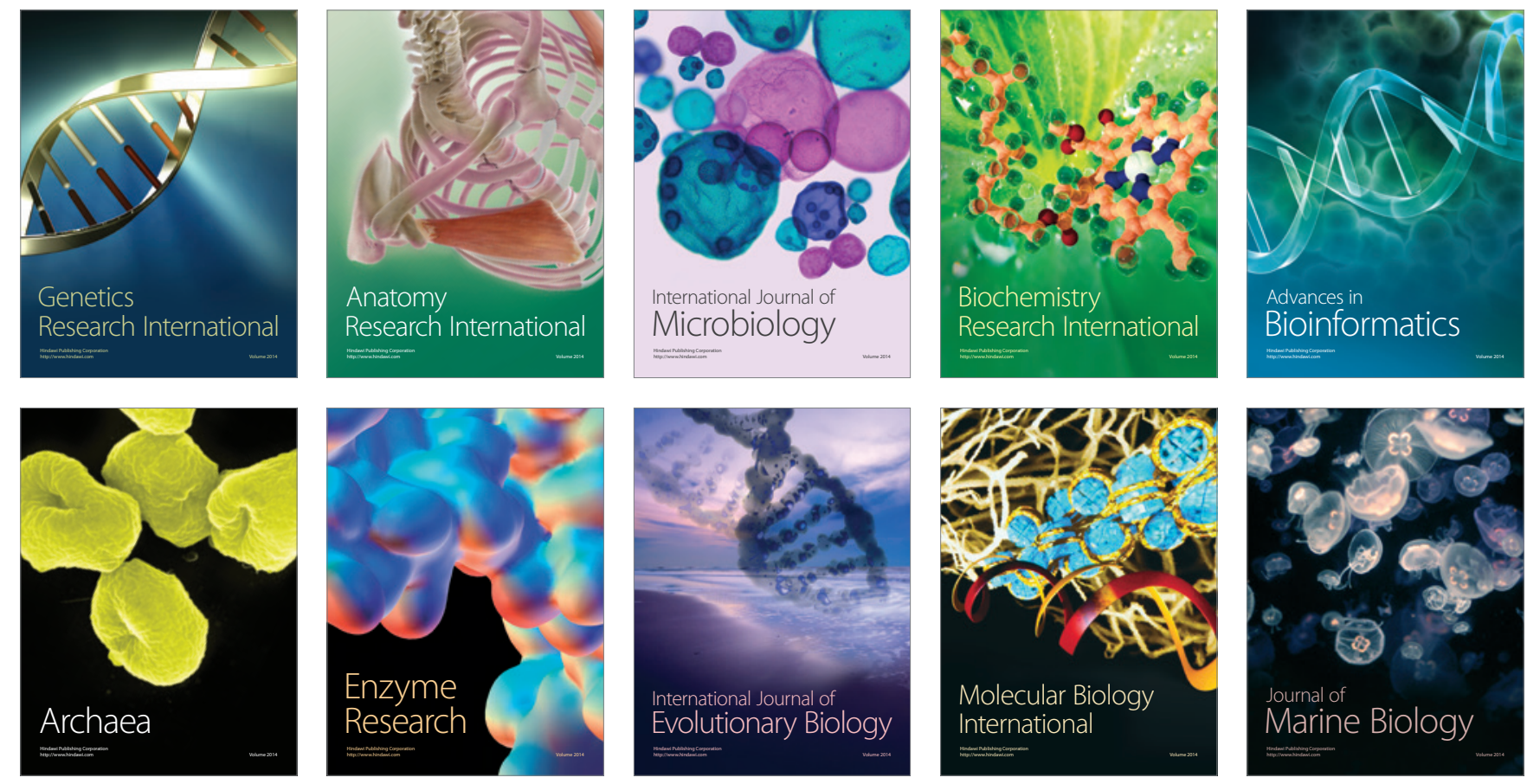